\title{
Modulation of the insulin anabolic signalling cascade in growing chickens by $n-3$ PUFA
}

\author{
Sophie Tesseraud $^{1 *}$, Pascal Chartrin ${ }^{1}$, Sonia Métayer-Coustard ${ }^{1}$, Dominique Hermier ${ }^{2,3}$, \\ Noémie Simon ${ }^{4}$, Corinne Peyronnet ${ }^{4}$, Michel Lessire ${ }^{1}$ and Elisabeth Baéza ${ }^{1}$ \\ ${ }^{1}$ INRA, UR83 Recherches Avicoles, F-37380 Nouzilly, France \\ ${ }^{2}$ INRA, UMR914 Nutrition Physiology and Ingestive Behaviour, F-75231 Paris, France \\ ${ }^{3}$ AgroParisTech, UMR914 Nutrition Physiology and Ingestive Behaviour, F-75231 Paris, France \\ ${ }^{4}$ ONIDOL, 11 rue de Monceau, F-75008 Paris, France \\ (Submitted 18 April 2013 - Final revision received 1 August 2013 - Accepted 19 August 2013 - First published online 7 October 2013)
}

\section{Abstract}

n-3 PUFA are crucial for health and development. Their effects as regulators of lipid and glucose metabolism are well documented. They also appear to affect protein metabolism, especially by acting on insulin sensitivity. The aim of the present study was to investigate the role of $n$-3 PUFA, i.e. the precursor $\alpha$-linolenic acid (ALA) $18: 3 n-3$ or long-chain PUFA (LC-PUFA), in chickens, by focusing on their potential function as co-regulators of the insulin anabolic signalling cascade. Ross male broilers were divided into six dietary treatment groups. Diets were isoproteic (22\% crude protein) and isoenergetic (12.54 MJ metabolisable energy $/ \mathrm{kg})$ and contained similar lipid levels (6\%) provided by different proportions of various lipid sources: oleic sunflower oil rich in $18: 1 n-9$ as control; fish oil rich in LC-PUFA; rapeseed and linseed oils providing ALA. The provision of diets enriched with $n$-3 PUFA, i.e. rich in LC-PUFA or in the precursor ALA, for 3 weeks improved the growth performance of chickens, whereas that of only the ALA diet enhanced the development of the pectoralis major muscle. At $23 \mathrm{~d}$ of age, we studied the insulin sensitivity of the pectoralis major muscle and liver of chickens after an intravenous injection of insulin or saline. The present results indicate that the activation patterns of $n-3$ PUFA are different in the liver and muscles. An ALA-enriched diet may improve insulin sensitivity in muscles, with greater activation of the insulin-induced $70 \mathrm{kDa}$ ribosomal protein $\mathrm{S} 6 \mathrm{kinase} / \mathrm{ribosomal}$ protein 56 pathway involved in the translation of mRNA into proteins, thereby potentially increasing muscle protein synthesis and growth. Our findings provide a basis on which to optimise dietary fatty acid provision in growing animals.

Key words: $\boldsymbol{n}$-3 Fatty acids: Insulin signalling: Metabolism: Growth: Chickens

n-3 PUFA are crucial for health, normal development and organ functioning in vertebrates. Their effects as regulators of lipid and glucose metabolism are well documented. The action of $n$-3 PUFA on the transcription of key genes of lipid metabolism has been the most extensively studied aspect, particularly via their ligands, i.e. $\operatorname{PPAR}^{(1)}$. In contrast, little has been established regarding the mechanisms controlling protein metabolism in response to the provision of $n-3$ PUFA. Recent studies have indicated that the consumption of long-chain (LC) PUFA promotes protein anabolism ${ }^{(2-5)}$. In this case, $n-3$ PUFA may act by increasing insulin sensitivity rather than by regulating gene transcription. It should be noted that these studies had been carried out using LC-PUFA found in abundance in fish oils (e.g. EPA and DHA) and that the effects of the plant precursor $\alpha$-linolenic acid (ALA, $18: 3 n-3)$ have never been explored.
Insulin is a major regulator of glucose metabolism and is also an anabolic hormone known to regulate protein metabolism (for a review, see Tesseraud et al. ${ }^{(6)}$ ). Insulin acts via the activation of its receptor, the role of which is to recognise the hormone and to initiate a cascade of intracellular events. The insulin signal is mediated by the activation of intracellular kinases such as protein kinase B (also called AKT), affecting the phosphorylation ( $\mathrm{p}$ ) of some major effectors involved in the regulation of protein synthesis (e.g. p70S6 kinase, also called $70 \mathrm{kDa}$ ribosomal protein $\mathrm{S} 6$ kinase (S6K1)) Cytoplasmic serine/threonine S6K1 is stimulated after a single insulin injection in chickens, as in other species, and phosphorylates several proteins, including the ribosomal protein $\mathrm{S} 6$ (S6), affecting the initiation stage of mRNA translation $^{(7-10)}$. Muscle mass depends on the dynamic balance between the processes of protein synthesis and degradation.

Abbreviations: ALA, $\alpha$-linolenic acid; FA, fatty acid; LC, long chain; MuRF1, muscle ring finger-1; p, phosphorylation; S6, ribosomal protein S6; S6K1, 70 kDA ribosomal protein $\mathrm{S} 6$ kinase.

*Corresponding author: Dr S. Tesseraud, fax +332474277 78, email sophie.tesseraud@tours.inra.fr 
Studies on gene expression profiling have highlighted genes specifically induced during atrophy (atrophy-related genes, also called atrogenes) and involved in proteolysis, i.e. muscle atrophy $\mathrm{F}$ box (MAFbx or atrogin-1) and muscle ring finger-1 (MuRF1) ${ }^{(11,12)}$. These two important genes control the polyubiquitination and thus the degradation of certain proteins, including myofibrillar proteins ${ }^{(13-15)}$. They are regulated by hormones such as insulin via mechanisms involving the AKT signalling pathway ${ }^{(16-18)}$. The aim of the present study was, therefore, to investigate the role of $n-3$ PUFA (ALA or LC-PUFA) in growth and protein metabolism in chickens, by focusing on their potential function as co-regulators of the insulin signalling cascade.

\section{Materials and methods}

\section{Broiler chickens and feed distribution}

A total of 960 male broiler chicks (Gallus gallus; Ross 708 strain) were obtained at $1 \mathrm{~d}$ of age from a hatchery (Grolier), wing-banded and randomly distributed into forty-eight pens $(1.6 \times 1.75 \mathrm{~m}$, twenty chicks per pen) in a conventional environmentally controlled poultry shed at the Poultry Research Centre in Nouzilly, France. The floor was covered with wood shavings. Lighting was reduced from 23L:1D to $18 \mathrm{~L}: 6 \mathrm{D}$ daily after the age of $3 \mathrm{~d}$. Environmental temperature was progressively reduced from 31 to $22^{\circ} \mathrm{C}$. Feed was provided in circular feeders. Chickens had ad libitum access to food and water.

To investigate the effects of LC-PUFA and their precursor, i.e. ALA, six diets were used (Table 1). The diets were isoproteic (22\% crude protein) and isoenergetic (12.54 MJ $\mathrm{ME} / \mathrm{kg}$ ) and contained the same lipid percentage (6\%) provided by different oils. The control diet contained oleic sunflower oil rich in 18:1n-9: Oleic diet, 6\% oleic sunflower oil. Among the experimental test diets used, three were differentially enriched with ALA from rapeseed oil and linseed oil: ALA( $(-)$ diet, $6 \%$ rapeseed oil; ALA diet, $4 \%$ rapeseed oil and $2 \%$ linseed oil; ALA(+) diet, $2 \%$ rapeseed oil and $4 \%$ linseed oil. The remaining two diets were enriched with LC $n$-3 PUFA from fish oil: LC-PUFA diet, $4 \%$ oleic sunflower oil and $2 \%$ fish oil, and LC-PUFA(+) diet, $6 \%$ fish oil.

Chickens were individually weighed at 1, 21 and $23 \mathrm{~d}$ of age. Feed intake was determined per pen, and feed conversion ratio was calculated for the whole experimental period. At $21 \mathrm{~d}$ of age, after $7 \mathrm{~h}$ of feed withdrawal, 120 birds ( $n 20$ per diet) chosen at random were weighed and killed, and the carcasses were processed as described previously ${ }^{(19)}$. The legs (thighs + drumsticks) and livers were stored at $-20^{\circ} \mathrm{C}$ for chemical analysis. At $23 \mathrm{~d}$ of age, $16 \mathrm{~h}$ food-deprived chickens ( $n$ 6-7) were injected intravenously with either insulin ( $1 \mathrm{U} / \mathrm{kg}(6.9 \mathrm{mmol} / \mathrm{kg})$; Umuline Rapide, Lilly France) or saline solution $(0.9 \% \mathrm{NaCl})$ to investigate the potential dietrelated modulation of the insulin cascade. Chickens were killed 15 min after treatment by decapitation following blood sampling. The right pectoralis major and sartorius (i.e. a leg muscle) muscles and the livers were removed, weighed, sampled, quickly frozen in liquid $\mathrm{N}_{2}$ and stored at $-80^{\circ} \mathrm{C}$. Plasma was stored at $-20^{\circ} \mathrm{C}$ until further analysis. All the experiments were carried out with due regard to legislation governing the ethical treatment of animals, and investigators were certified by the French government to carry out animal experiments.

Table 1. Composition (\%) and characteristics of the experimental diets*

\begin{tabular}{lcccccc}
\hline Ingredients & Oleic & ALA $(-)$ & ALA & ALA $(+)$ & LC-PUFA & LC-PUFA $(+)$ \\
\hline Peas & 8.00 & 8.00 & 8.00 & 8.00 & 8.00 & 8.00 \\
Wheat & 48.15 & 48.15 & 48.15 & 48.15 & 48.15 & 48.15 \\
Oleic sunflower oil & 6.00 & - & - & - & 4.00 & - \\
Rapeseed oil & - & 6.00 & 4.00 & 2.00 & - & - \\
Linseed oil & - & - & 2.00 & 4.00 & - & - \\
Fish oil & - & - & - & - & 2.00 & 6.00 \\
Soyabean meal & 34.32 & 34.32 & 34.32 & 34.32 & 34.32 & 34.32 \\
Calcium carbonate & 1.04 & 1.04 & 1.04 & 1.04 & 1.04 & 1.04 \\
Dicalcium phosphate & 1.47 & 1.47 & 1.47 & 1.47 & 1.47 & 1.47 \\
Salt & 0.30 & 0.30 & 0.30 & 0.30 & 0.30 & 0.30 \\
Premix† & 0.50 & 0.50 & 0.50 & 0.50 & 0.50 & 0.50 \\
DL-Met & 0.17 & 0.17 & 0.17 & 0.17 & 0.17 & 0.17 \\
Anticoccidial & 0.05 & 0.05 & 0.05 & 0.05 & 0.05 & 0.05 \\
Calculated content & & & & & & \\
$\quad$ ME (MJ/kg) & 12.54 & 12.54 & 12.54 & 12.54 & 12.54 & 12.54 \\
CP (\%, analysed) & 22.07 & 22.24 & 22.33 & 22.42 & 22.52 & 22.39 \\
Fat (\%, analysed) & 7.30 & 7.56 & 7.48 & 7.52 & 7.44 & 7.31 \\
Lys (\%) & 1.20 & 1.20 & 1.20 & 1.20 & 1.20 & 1.20 \\
SAA (\%) & 0.85 & 0.85 & 0.85 & 0.85 & 0.85 & 0.85 \\
Thr (\%) & 0.82 & 0.82 & 0.82 & 0.82 & 0.82 & 0.82 \\
Tryptophan (\%) & 0.27 & 0.27 & 0.27 & 0.27 & 0.27 & 0.27 \\
Ca (\%) & 1.00 & 1.00 & 1.00 & 1.00 & 1.00 & 1.00 \\
Available P (\%) & 0.40 & 0.40 & 0.40 & 0.40 & 0.40 & 0.40 \\
\hline
\end{tabular}

ALA, $\alpha$-linolenic acid; LC, long-chain; CP, crude protein; SAA, sulphur amino acids

* Oleic, diet containing $6 \%$ oleic sunflower oil rich in monounsaturated 18:1; ALA $(-), A L A$ and ALA $(+)$, diets enriched with ALA

from rapeseed and/or linseed oils; LC-PUFA and LC-PUFA(+), diets enriched with LC $n$-3 PUFA from fish oil.

†Composition as described previously ${ }^{(28)}$. 


\section{Plasma parameters and tissue characteristics}

Plasma $\alpha$-amino-non-protein $\mathrm{N}$ concentrations (providing an estimate of total free amino acids) were measured after extraction with $10 \%(\mathrm{v} / \mathrm{v})$ sulphosalicylic acid, using $2 \%$ ninhydrin reagent (Sigma Chemicals) and L-serine as the standard ${ }^{(20)}$. Plasma TAG and uric acid concentrations were quantified by colorimetric enzymatic methods using kits obtained from bioMérieux according to the methods of Fossati \& Prencipe ${ }^{(21)}$ and Artiss \& Entwistle ${ }^{(22)}$. Plasma glucose concentration was quantified by the colorimetric enzymatic methods of Trinder ${ }^{(23)}$ using a kit obtained from Sobioda.

Glycolytic potential represents an estimate of tissue glycogen concentration during killing ${ }^{(24)}$. It takes into account the main intermediates of glycogen degradation in live and post-mortem tissue and therefore represents an estimate of the in vivo glycogen concentration. Glycogen, glucose-6-phosphate, free glucose and lactate concentrations were measured in liver samples by enzymatic procedures according to the method of Dalrymple \& Hamm $^{(25)}$. Glycolytic potential was calculated according to the following formula: glycolytic potential $=2$ (glycogen + glucose + glucose-6-phosphate $)+$ lactate, and it is expressed as $\mu \mathrm{mol}$ of lactate equivalent per $\mathrm{g}$ of tissue.

\section{Chemical analysis}

Total lipids were extracted quantitatively from diets and from samples of minced livers and leg muscles comprising intramuscular fat (amounts of diet and tissue samples adjusted on the basis of expected lipid contents for accurate Folch lipid extraction) by homogenisation in chloroform-methanol $(2: 1, v / v)$, and then collected gravimetrically ${ }^{(26)}$. Fatty acid (FA) composition was determined after transmethylation of lipids ${ }^{\text {(27) }}$ by GC (Perkin Elmer Autosystem). Injector and detector (flame ionisation detector) temperatures were set at $250^{\circ} \mathrm{C}$; the carrier gas was $\mathrm{N}$ with a head column pressure of 16.5 psi. We used a capillary column (BPX70, SGE). Methyl esters were identified and quantified by comparison with standards (Sigma).

\section{RNA isolation and RT-PCR}

Total RNA was extracted using RNA Now (Biogentec) from $100 \mathrm{mg}$ of tissue samples according to the manufacturer's recommendations. After RNase-free DNase treatment, RNA was reverse-transcribed using Super Script II RNase H Reverse transcriptase (Invitrogen) in the presence of random primers (Promega). Quantitative PCR were carried out in duplicate using the LightCycler ${ }^{\circledR} 480$ II apparatus (Roche). The primers chosen to study the expression of MuRF1, atrogin-1, $\beta$-actin, hepatic carnitine palmitoyltransferase 1 (bCPT1), FA synthase (FAS), sterol regulatory element-binding protein 1 (SREBP1), $P P A R \alpha, P P A R \delta$ and PPAR $\gamma$ had been used previously in our laboratory ${ }^{(20,28,29)}$. The sequences of primers used for studying the expression of carbohydrate-responsive element-binding protein (ChREBP) (MLXIPL), FA translocase (Cd36), diacylglycerol $O$-acyltransferase 2 (DGAT2), FA desaturase 1 or delta- 5 desaturase (FADS1), glyceraldehyde 3-phosphate dehydrogenase
$(G A P D H)$, microsomal TAG transfer protein $(M T T P)$ and stearoyl-CoA desaturase 1 or delta-9 desaturase (SCD1), specifically designed or reproduced from the literature ${ }^{(30)}$, are given in Table S1 (available online). The cycling conditions consisted of a denaturation step $\left(95^{\circ} \mathrm{C}\right.$ for $\left.10 \mathrm{~min}\right)$ and forty-five cycles of amplification, including both denaturation for $15 \mathrm{~s}$ at $95^{\circ} \mathrm{C}$ and annealing-extension for $30 \mathrm{~s} \mathrm{(} 1 \mathrm{~min}$ for $M T T P)$ at $60^{\circ} \mathrm{C}$. At the end of the PCR, dissociation was carried out by slowly heating the samples from 60 to $95^{\circ} \mathrm{C}$ and continuous recording of the decrease in SYBR Green fluorescence resulting from the dissociation of double-stranded DNA. Gene expression levels were estimated on the basis of PCR efficiency and threshold cycle $\left(C_{\mathrm{t}}\right)$ deviation of an unknown sample $v$. a reference sample, as described previously ${ }^{(31)}$. The genes $\beta$-actin (muscle) and GAPDH (liver) were chosen as references.

\section{Western blotting}

To analyse the insulin signalling cascade involved in the regulation of protein metabolism, muscle and liver lysates were prepared as described previously ${ }^{(9)}$. Muscle lysates ( $60 \mu \mathrm{g}$ of protein) were subjected to SDS-PAGE and Western blotting using the appropriate antibodies: p-S6K1 (T389), p-S6K1 (T421/S424), p-AKT (S473), p-AKT (T308) and p-S6 (S235/S236) (Cell Signaling Technology); S6K1 (Santa Cruz Biotechnology); vinculin (Sigma Chemical Company). These commercial antibodies directed against mammalian proteins have been previously shown to cross-react with chicken homologue protein to a good extent ${ }^{(9)}$. After washing, membranes were incubated with Alexa Fluor secondary antibodies (Molecular Probes, Interchim). Bands were visualised by IR fluorescence using the Odyssey ${ }^{\circledR}$ Imaging System (LI-COR, Inc. Biotechnology) and quantified using the Odyssey Infrared Imaging System software (application software, version 1.2).

\section{0 kDa ribosomal protein 56 kinase assay}

The activity of S6K1 enzyme was measured by quantifying the incorporation of $\left[{ }^{33} \mathrm{P}\right]$-ATP in eleven amino acids of the S6 sequence $\left({ }^{229}\right.$ AKRRRLSSLRA ${ }^{239}$ ) according to the manufacturer's instructions (Upstate Cell Signaling), as described previously $^{(7)}$.

\section{Statistical analysis}

Values are presented as means with their standard errors. Data were processed using the StatView Software program, version 5 (SAS Institute). Data were subjected to ANOVA by considering diet and treatment (insulin $v$. control) as the main effects and their interactions in the model. The means were compared by Fisher's least significant difference test in the case of a significant effect. For gene expression, no effect of treatment or an interaction between diet and treatment was observed. For the sake of clarity, data were, therefore, pooled across the treatments (i.e. control and insulin groups were pooled) and analysed again by considering diet as the main effect. $P(0.05$ was considered statistically significant. 
Table 2. Growth performance and body composition of chickens fed diets containing different sources of lipids

\begin{tabular}{|c|c|c|c|c|c|c|c|c|}
\hline Diets $^{*}$ & Oleic & $\operatorname{ALA}(-)$ & ALA & $\operatorname{ALA}(+)$ & LC-PUFA & LC-PUFA(+) & SEM & $P$ \\
\hline \multicolumn{9}{|c|}{ Growth performance (day 1 to day 21 ) } \\
\hline Final BW (g) $(n 160)$ & $892^{c}$ & $907^{\mathrm{b}, \mathrm{c}}$ & $926^{a, b}$ & $933^{\mathrm{a}}$ & $932^{\mathrm{a}}$ & $901^{\mathrm{c}}$ & 95 & $<0.001$ \\
\hline FCR† $(n 8)$ & 1.33 & 1.36 & $1 \cdot 32$ & 1.32 & 1.33 & 1.33 & 0.03 & 0.17 \\
\hline \multicolumn{9}{|c|}{ Body composition on day $21(n 20)$} \\
\hline Abdominal fat (\% BW) & 1.39 & 1.49 & 1.43 & 1.48 & 1.52 & 1.43 & 0.26 & 0.62 \\
\hline Leg $\neq(\%$ BW $)$ & $20 \cdot 2$ & $20 \cdot 1$ & $20 \cdot 2$ & 20.4 & $20 \cdot 3$ & $20 \cdot 1$ & 0.75 & 0.62 \\
\hline Liver (\% BW) & $2 \cdot 46^{\mathrm{b}, \mathrm{c}}$ & $2.47^{\mathrm{b}}$ & $2 \cdot 41^{\mathrm{b}, \mathrm{c}}$ & $2 \cdot 34^{\mathrm{c}}$ & $2.50^{\mathrm{b}}$ & $2 \cdot 86^{\mathrm{a}}$ & 0.19 & $<0.001$ \\
\hline
\end{tabular}

ALA, $\alpha$-linolenic acid; LC, long-chain; BW, body weight; FCR, feed conversion ratio.

a,b,c Mean values within a row with unlike superscript letters were significantly different $(P<0.05)$.

*Oleic, diet containing $6 \%$ oleic sunflower oil rich in monounsaturated 18:1; ALA(-), ALA and ALA(+), diets enriched with ALA from rapeseed and/or linseed oils; LC-PUFA and LC-PUFA $(+)$, diets enriched with LC $n$-3 PUFA from fish oil.

$\dagger$ Calculated from feed intake determined per pen $(n 8)$.

$\ddagger$ Leg, thighs + drumsticks.

\section{Results}

\section{Animal characteristics}

There was a significant effect of diet on body weight $(P<0 \cdot 001$; Table 2), but not on the feed conversion ratio. Chickens fed the ALA, ALA $(+)$ and LC-PUFA diets weighed significantly more than those fed the Oleic diet or the LCPUFA( + ) diet $(P<0 \cdot 05)$. The weights of chickens fed the $\operatorname{ALA}(-)$ diet were not significantly different from those of chickens fed the Oleic diet, but were lower than those of chickens fed the ALA $(+)$ diet containing rapeseed oil but enriched with linseed oil. With regard to body composition (Table 2), the abdominal fat percentage, an accurate indicator of carcass fatness, and leg yield were not affected by the experimental diets. Conversely, there was a clear effect of diet on the relative weights of the livers $(P<0.001)$, with the heaviest being found in the LC-PUFA $(+)$ group. Based on these findings, all the other measurements were carried out for three of the six dietary treatments under study: the Oleic diet as the control diet; the ALA diet with intermediate enrichment with ALA; the LC-PUFA diet with moderate PUFA supply (FA composition given in Table 3). As expected, the Oleic, ALA and LC-PUFA diets were the richest in oleic acid, ALA and $n$-3 LC-PUFA, respectively. The FA composition of the leg muscles and liver is given in Table 4. The levels of saturated FA, particularly 18:0, and those of PUFA, particularly $n$-3 LC-PUFA, were much higher in the liver than in the leg muscles. The reverse was observed for the levels of MUFA. The FA composition of the liver and leg muscles tended to reflect that of the diets. Indeed, 18:1 content was 1.2- to 1.5-fold higher in the Oleic group than in the ALA and LC-PUFA groups. ALA content was dramatically increased by the provision of the ALA diet. Similarly, the LC-PUFA diet was the most effective in increasing $n$ - 3 LC-PUFA content in the leg muscles and even more so in the liver. However, the percentages of all $n$ - 3 LC-PUFA were also higher in the ALA group than in the Oleic group, as a result of the bioconversion of ALA into its LC derivatives. It should also be noted that chicken livers exhibited percentages of $n$-3 LC-PUFA that were higher than those found in the diets, which did not exceed $6.5 \%$. With regard to $n-6$ PUFA, linoleic acid content $(18: 2 n-6)$ reflected that of the diets, with levels being highest in both the livers and leg muscles of the ALA group. The proportion of arachidonic acid (20:4n-6) was low in the leg muscles and did not vary with the diet. This percentage in the liver decreased as the percentage of $n-3$ LC-PUFA increased, being lowest in the LC-PUFA group. Lipid content was significantly lower in the livers of chickens fed the diets enriched with $n-3$ PUFA ( $P<0 \cdot 01$ ); a similar trend, albeit not significant, was observed in the leg muscles.

Insulin responses were investigated in chickens fed the Oleic, ALA and LC-PUFA diets. No significant effect of insulin treatment that would have affected the study was observed on body weight or tissue weight (well-matched groups; Table 5). Chickens fed the ALA and LC-PUFA diets were heavier than those fed the Oleic diet (i.e. selected chickens were representative of each dietary treatment tested). The effects of insulin

Table 3. Fatty acid composition of the Oleic, $\alpha$-linolenic acid (ALA) and long-chain (LC)-PUFA experimental diets expressed as a percentage of total fatty acids

\begin{tabular}{|c|c|c|c|}
\hline Diets* & Oleic & ALA & LC-PUFA \\
\hline 14:0 & 0.05 & 0.12 & 1.70 \\
\hline $16: 0$ & 6.39 & 6.89 & 9.83 \\
\hline $18: 0$ & $2 \cdot 80$ & 2.03 & $2 \cdot 86$ \\
\hline $20: 0$ & - & 0.21 & 0.39 \\
\hline $22: 0$ & 0.44 & - & - \\
\hline $16: 1 n-7$ & 0.00 & $0 \cdot 10$ & 1.89 \\
\hline $18: 1 n-9$ & 68.90 & 48.05 & 55.82 \\
\hline $20: 1 n-9$ & - & 0.68 & 0.20 \\
\hline $18: 2 n-6$ & $20 \cdot 22$ & 25.95 & $18 \cdot 26$ \\
\hline $18: 3 n-3$ (ALA) & $1 \cdot 21$ & $15 \cdot 83$ & $2 \cdot 83$ \\
\hline $20: 5 n-3$ (EPA) & - & - & 3.75 \\
\hline $22: 5 n-3$ (DPA) & - & 0.07 & 0.25 \\
\hline $22: 6 n-3$ (DHA) & - & 0.08 & 2.22 \\
\hline Total SFA & $9 \cdot 68$ & $9 \cdot 25$ & $14 \cdot 78$ \\
\hline Total MUFA & 68.90 & 48.83 & 57.91 \\
\hline Total PUFA & 21.43 & 41.93 & $27 \cdot 31$ \\
\hline$n-6 \dagger$ & $20 \cdot 22$ & $25 \cdot 95$ & $18 \cdot 26$ \\
\hline$n-3 \dagger$ & $1 \cdot 21$ & 15.98 & 9.05 \\
\hline$n-6: n-3 \dagger$ & $16 \cdot 71$ & $1 \cdot 62$ & 2.02 \\
\hline$n-3 \mathrm{LC}+$ & - & 0.15 & $6 \cdot 22$ \\
\hline
\end{tabular}

DPA, docosapentaenoic acid.

* Oleic, diet containing oleic sunflower oil rich in monounsaturated 18:1; ALA, diet enriched with ALA from rapeseed and linseed oils; LC-PUFA, diet enriched with LC $n$-3 PUFA from fish oil.

† $n-6$, total $n-6$ FA; $n-3$, total $n-3$ FA; $n-6: n-3$, ratio of total $n-6$ FA:total $n-3$ FA; $n-3$ LC, sum of $20: 5 n-3,22: 5 n-3$ and $22: 6 n-3$. 
Table 4. Fatty acid composition (as a percentage of total fatty acids) and lipid content (\%) of the leg muscles and livers of 21-d-old chickens fed the Oleic, $\alpha$-linolenic acid (ALA) and long-chain (LC)-PUFA experimental diets

(Mean values with their standard errors, $n 12$ )

\begin{tabular}{|c|c|c|c|c|c|c|c|c|c|c|}
\hline \multirow{2}{*}{$\begin{array}{l}\text { Tissues... } \\
\text { Diets }^{\star}\end{array}$} & \multicolumn{5}{|c|}{ Leg muscles } & \multicolumn{5}{|c|}{ Liver } \\
\hline & Oleic & ALA & LC-PUFA & SEM & $P$ & Oleic & ALA & LC-PUFA & SEM & $P$ \\
\hline $14: 0$ & $0.23^{b}$ & $0.27^{b}$ & $0.99^{a}$ & 0.31 & $<0.001$ & - & - & - & & - \\
\hline $16: 0$ & $16 \cdot 32^{c}$ & $17 \cdot 07^{b}$ & $18 \cdot 56^{\mathrm{a}}$ & 1.00 & $<0.001$ & $18 \cdot 31^{b}$ & $17 \cdot 99^{b}$ & $21 \cdot 20^{\mathrm{a}}$ & 1.24 & $<0.001$ \\
\hline $18: 0$ & $5 \cdot 29$ & $5 \cdot 54$ & $5 \cdot 68$ & 0.53 & 0.35 & $21 \cdot 83$ & 23.97 & 22.57 & $2 \cdot 13$ & 0.16 \\
\hline $16: 1 n-7$ & $3.00^{\mathrm{b}}$ & $2 \cdot 96^{\mathrm{b}}$ & $4.43^{\mathrm{a}}$ & 0.69 & $<0.001$ & 0.42 & 0.35 & 0.39 & 0.43 & 0.94 \\
\hline $18: 1 n-9$ & $60 \cdot 93^{a}$ & $46 \cdot 83^{c}$ & $52 \cdot 87^{\mathrm{b}}$ & 4.87 & $<0.001$ & $27 \cdot 27^{a}$ & $17 \cdot 93^{b}$ & $18 \cdot 65^{\mathrm{b}}$ & 5.80 & $<0.001$ \\
\hline $20: 1 n-9$ & $0.25^{\mathrm{a}}$ & $0 \cdot 31^{\mathrm{a}}$ & $0.08^{b}$ & 0.13 & $<0.001$ & - & - & - & & - \\
\hline $18: 2 n-6$ & $12 \cdot 81^{\mathrm{b}}$ & $17.05^{a}$ & $12 \cdot 70^{\mathrm{b}}$ & 1.91 & $<0.001$ & $17 \cdot 58^{\mathrm{a}}$ & $18 \cdot 45^{a}$ & $11 \cdot 48^{\mathrm{b}}$ & 3.12 & $<0.001$ \\
\hline $18: 3 n-3$ & $0.77^{\mathrm{b}}$ & $9 \cdot 33^{\mathrm{a}}$ & $1.07^{\mathrm{b}}$ & 3.75 & $<0.001$ & $0.37^{\mathrm{b}}$ & $2 \cdot 70^{\mathrm{a}}$ & $0.09^{b}$ & 1.24 & $<0.001$ \\
\hline $20: 4 n-6$ & 0.40 & 0.23 & 0.25 & 0.18 & 0.26 & $8 \cdot 58^{a}$ & $6 \cdot 48^{\mathrm{b}}$ & $3.65^{c}$ & $2 \cdot 16$ & $<0.001$ \\
\hline $20: 5 n-3$ & $0.01^{\mathrm{c}}$ & $0.21^{b}$ & $1.57^{\mathrm{a}}$ & 0.65 & $<0.001$ & $1.34^{\mathrm{C}}$ & $4 \cdot 13^{\mathrm{b}}$ & $6 \cdot 76^{\mathrm{a}}$ & 2.33 & $<0.001$ \\
\hline $22: 5 n-3$ & $0.00^{c}$ & $0.18^{\mathrm{b}}$ & $0.62^{\mathrm{a}}$ & 0.25 & $<0.001$ & $1.09^{b}$ & $1.96^{\mathrm{a}}$ & $2 \cdot 11^{\mathrm{a}}$ & 0.58 & $<0.001$ \\
\hline $22: 6 n-3$ & $0.00^{\mathrm{b}}$ & $0.03^{b}$ & $1 \cdot 20^{\mathrm{a}}$ & 0.53 & $<0.001$ & $3 \cdot 20^{c}$ & $6 \cdot 04^{b}$ & $14.09^{a}$ & $4 \cdot 60$ & $<0.001$ \\
\hline Total SFA & $21 \cdot 83^{b}$ & $22 \cdot 87^{b}$ & $25 \cdot 23^{\mathrm{a}}$ & 1.48 & $<0.001$ & $40 \cdot 14$ & 41.96 & $42 \cdot 77$ & 2.55 & 0.17 \\
\hline Total MUFA & $64 \cdot 18^{a}$ & $50 \cdot 06^{c}$ & $57 \cdot 38^{b}$ & 4.78 & $<0.001$ & $27 \cdot 69^{a}$ & $18 \cdot 28^{b}$ & $19 \cdot 05^{b}$ & 5.99 & 0.01 \\
\hline Total PUFA & $13.99^{c}$ & $27 \cdot 06^{a}$ & $17 \cdot 40^{\mathrm{b}}$ & 5.05 & $<0.001$ & $32 \cdot 17^{b}$ & $39.76^{a}$ & $38 \cdot 19^{a}$ & $4 \cdot 22$ & $<0.001$ \\
\hline$n-6 \dagger$ & $13 \cdot 21^{\mathrm{b}}$ & $17 \cdot 28^{\mathrm{a}}$ & $12 \cdot 95^{\mathrm{b}}$ & 1.91 & $<0.001$ & $26 \cdot 17^{a}$ & $24.93^{a}$ & $15 \cdot 13^{b}$ & 4.96 & $<0.001$ \\
\hline$n-3 \dagger$ & $0.77^{\mathrm{c}}$ & $9 \cdot 77^{\mathrm{a}}$ & $4.45^{\mathrm{b}}$ & 3.21 & $<0.001$ & $6.00^{c}$ & $14 \cdot 83^{b}$ & $23.06^{a}$ & $7 \cdot 10$ & $<0.001$ \\
\hline$n-6: n-3+$ & $17.99^{\mathrm{a}}$ & $1.77^{\mathrm{b}}$ & $2 \cdot 97^{\mathrm{b}}$ & 6.95 & $<0.001$ & $8 \cdot 72^{\mathrm{a}}$ & $2 \cdot 25^{\mathrm{b}}$ & $0.66^{\mathrm{b}}$ & 3.95 & $<0.001$ \\
\hline$n-3$ LC† & $0.01^{b}$ & $0.43^{\mathrm{b}}$ & $3.39^{\mathrm{a}}$ & 1.41 & $<0.001$ & $5 \cdot 63^{c}$ & $12 \cdot 13^{b}$ & $22 \cdot 96^{\mathrm{a}}$ & 3.17 & $<0.001$ \\
\hline Lipid content & 6.69 & $6 \cdot 18$ & $5 \cdot 90$ & 1.15 & 0.41 & $4.38^{\mathrm{a}}$ & $3.54^{\mathrm{b}}$ & $3.95^{\mathrm{b}}$ & 0.48 & $<0.01$ \\
\hline
\end{tabular}

a,b,c Mean values with unlike superscript letters were significantly different $(P<0.05)$.

* Oleic, diet containing oleic sunflower oil rich in monounsaturated 18:1; ALA, diet enriched with ALA from rapeseed and linseed oils; LC-PUFA, diet enriched with LC $n$-3 PUFA from fish oil.

† $n-6$, total $n-6$ FA; $n-3$, total $n-3$ FA; $n-6: n-3$, ratio of total $n-6$ FA:total $n-3$ FA; $n-3$ LC, sum of $20: 5 n-3,22: 5 n-3$ and $22: 6 n-3$.

treatment were significant for all the three diets with regard to glucose, TAG and uric acid concentrations, but not with regard to free amino acid concentrations. The diets had no effect on glucose, uric acid and amino acid concentrations. The only notable difference was the lower concentration of TAG in the LC-PUFA group compared with the concentration in the Oleic and ALA groups $(P<0 \cdot 01)$. The weight of the sartorius muscle was not affected by any diet. The pectoralis major muscle was heaviest in chickens fed the ALA diet than in those fed the other two diets $(P<0 \cdot 05)$, whereas liver weights of chickens fed the LC-PUFA diet were significantly higher than those of chickens fed the other two diets $(P<0 \cdot 001)$ The glycolytic potential in the liver was not modified by either the treatment or the diet. Similarly, there was no change in liver glycogen or lactate content (data not shown).

\section{Insulin signalling and gene expression in chicken breast muscle}

Since the ALA diet resulted in heavier pectoralis major muscles, we first studied the activity of S6K1 (a kinase controlling protein synthesis and growth) in the breast muscle of

Table 5. Body weight (BW), plasma parameters and tissue characteristics of 23-d-old chickens fed the Oleic, $\alpha$-linolenic acid (ALA) and long-chain (LC)-PUFA experimental diets and injected intravenously with either insulin or saline

(Mean values with their standard errors, $n 6-7$ )

\begin{tabular}{|c|c|c|c|c|c|c|c|c|c|c|}
\hline \multirow{2}{*}{$\begin{array}{l}\text { Diet }^{*} \ldots \\
\text { T† }\end{array}$} & \multicolumn{2}{|c|}{ Oleic } & \multicolumn{2}{|c|}{ ALA } & \multicolumn{2}{|c|}{ LC-PUFA } & \multirow[b]{2}{*}{ SEM } & \multicolumn{3}{|c|}{$P$} \\
\hline & $\mathrm{C}$ & 1 & $\mathrm{C}$ & 1 & $\mathrm{C}$ & 1 & & $\mathrm{D}$ & $\mathrm{T}$ & $\mathrm{D} \times \mathrm{T}$ \\
\hline $\begin{array}{l}\text { BW }(\mathrm{g}) \\
\text { Plasma parameters }\end{array}$ & 986 & 975 & 1010 & 1009 & 1010 & 1006 & $9 \cdot 1$ & $<0.01$ & 0.51 & 0.85 \\
\hline Glucose $(\mathrm{g} / \mathrm{l})$ & $2 \cdot 20$ & 1.42 & $2 \cdot 12$ & 1.42 & $2 \cdot 11$ & 1.51 & 0.07 & 0.83 & $<0.001$ & 0.46 \\
\hline TAG $(g / l)$ & 0.46 & 0.47 & 0.43 & 0.46 & 0.31 & 0.41 & 0.03 & $<0.01$ & $<0.05$ & 0.35 \\
\hline Uric acid $(\mathrm{mg} / \mathrm{ml})$ & 45.5 & 77.6 & $50 \cdot 5$ & $84 \cdot 7$ & $41 \cdot 7$ & $70 \cdot 0$ & 5.35 & 0.12 & $<0.001$ & 0.87 \\
\hline FAA $\ddagger(\mathrm{mg} / \mathrm{ml})$ & 0.75 & 0.89 & 0.83 & 0.60 & 0.82 & 0.64 & 0.15 & 0.83 & 0.56 & 0.57 \\
\hline \multicolumn{11}{|l|}{ Tissue characteristics } \\
\hline Pectoralis major weight $(\mathrm{g})$ & $62 \cdot 20$ & 64.08 & 66.09 & $68 \cdot 20$ & 62.55 & 62.97 & 1.83 & $<0.05$ & 0.34 & 0.89 \\
\hline Sartorius weight $(\mathrm{g})$ & 3.17 & 3.14 & 3.38 & 3.40 & 3.49 & 3.41 & $0 \cdot 16$ & 0.17 & 0.82 & 0.95 \\
\hline Liver weight $(\mathrm{g})$ & $22 \cdot 60$ & $22 \cdot 68$ & 21.57 & $22 \cdot 72$ & $24 \cdot 84$ & $25 \cdot 25$ & 0.56 & $<0.001$ & 0.26 & 0.65 \\
\hline Liver GP $\ddagger(\mu \mathrm{mol} / \mathrm{g})$ & 146 & 147 & 143 & 143 & 147 & 144 & $3 \cdot 6$ & 0.57 & 0.82 & 0.83 \\
\hline
\end{tabular}

D, diet; T, treatment; C, control; I, insulin; FAA, $\alpha-\mathrm{NH} 2$-non-protein nitrogen; GP, glycolytic potential.

* Oleic, diet containing oleic sunflower oil rich in monounsaturated 18:1; ALA, diet enriched with ALA from rapeseed and linseed oils; LC-PUFA, diet enriched with LC $n-3$ PUFA from fish oil.

†I $v$. saline (C).

¥FAA, an estimate of free amino acids, expressed as $\mathrm{mg}$ L-serine equivalent/ml; GP, expressed as $\mu$ mol of lactate equivalent per $\mathrm{g}$ of tissue. They were analysed using two-way ANOVA. 
chickens given an injection of insulin or saline (Fig. 1(A)). As expected, $15 \mathrm{~min}$ of insulin stimulation dramatically increased the activity of the kinase S6K1 in the pectoralis major muscle $(P<0.001)$. Interestingly, there was an effect of diet, with higher S6K1 activity being found in chickens fed the ALA diet than in those fed the other diets $(P<0.05)$. Consistent with this was the fact that the phosphorylation levels of the S6 were also significantly higher in chickens fed the ALA diet (shown by Western blots, Fig. 1(B)), confirming that the activation of S6K1 varied according to the diet.

We then analysed the phosphorylation of S6K1 at T389 and T421/S424, both sites believed to be required for the activation

(A)

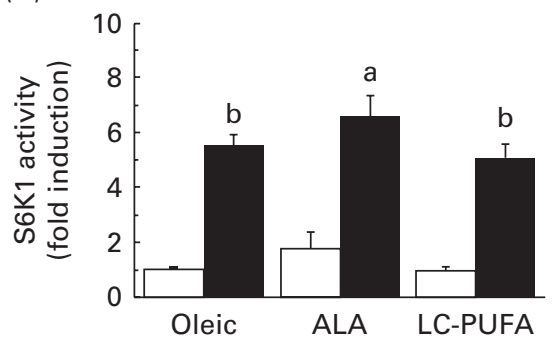

(C)
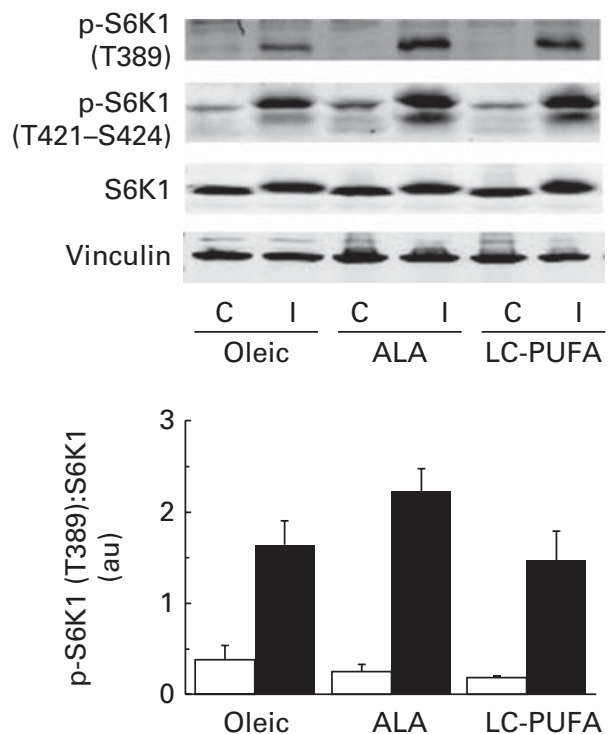

of S6K1 (Fig. 1(C)). Insulin increased the phosphorylation of the kinase in the pectoralis major muscle $(P<0 \cdot 001)$. There was clearly no effect of diet on the phosphorylation at T421/ S424. Although the slightly higher values of the ALA group did not reach statistical significance $(P<0 \cdot 10)$, the S6K1 pattern of phosphorylation at T389 was similar to that observed for the activity of S6K1 and the phosphorylation of S6. Relatively similar patterns of phosphorylation were also found for AKT at S473 and T308 upstream in the insulin cascade, but with wide variability in the insulin-treated groups (Fig. 2). We next explored the potential regulation of atrogin-1 and MuRF1 in the pectoralis major muscle. Under the
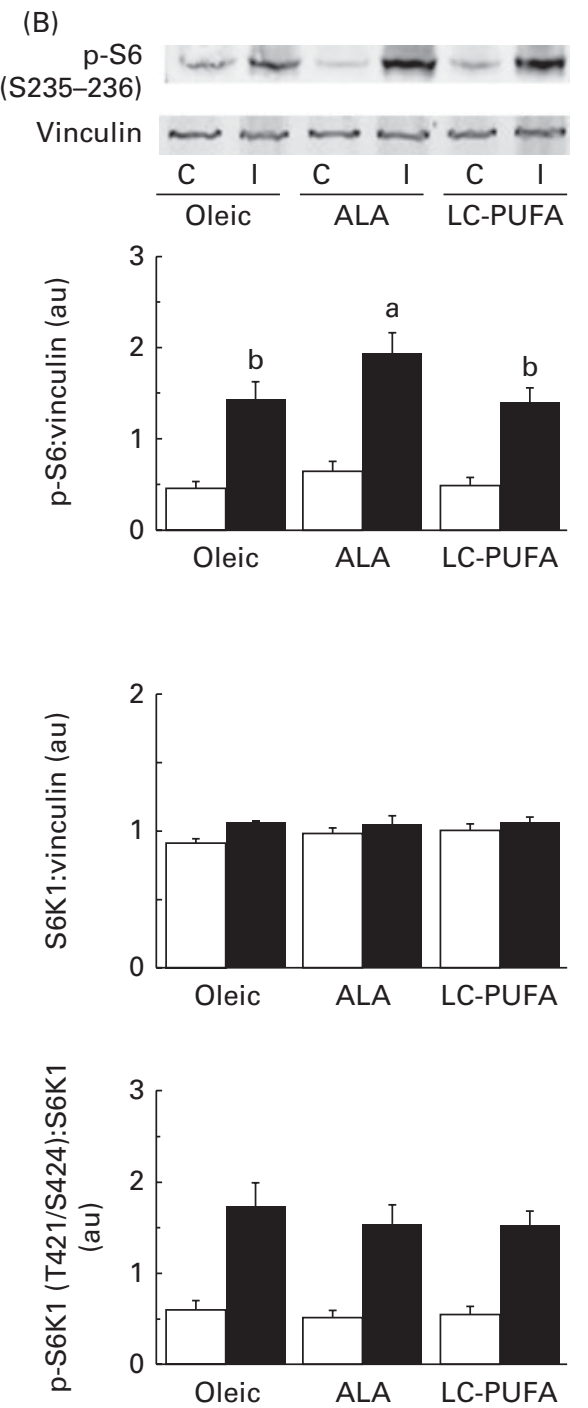

Fig. 1. Effects of insulin injection on $70 \mathrm{kDA}$ ribosomal protein $\mathrm{S} 6$ kinase (S6K1) activity and ribosomal protein S6 (S6) and S6K1 phosphorylation (p) levels in the breast muscle of 23-d-old chickens fed the Oleic (diet containing oleic sunflower oil rich in monounsaturated 18:1), $\alpha$-linolenic acid (ALA, diet enriched with ALA from rapeseed and linseed oils) and long-chain PUFA (LC-PUFA, diet enriched with LC $n$-3 PUFA from fish oil) experimental diets. The activity of (A) S6K1 in chickens food-deprived for $16 \mathrm{~h}$ and injected intravenously with either insulin (I, $\square)$ or saline solution (control, $C(\square)$ ). The activity of the enzyme was measured by quantifying the incorporation of $\gamma^{-33}$ p-ATP in eleven amino acids of the S6 sequence. Values are means $(n 6-7)$, with their standard errors represented by vertical bars and are expressed as the level of stimulation above that in the control muscle in chickens fed the Oleic diet. They were analysed using two-way ANOVA. There was no diet $x$ treatment interaction. ${ }^{a, b}$ Unlike letters indicate significant differences between diets $(P<0.05)$. The phosphorylation of (B) S6 and (C) S6K1 in chickens food-deprived for $16 \mathrm{~h}$ and injected intravenously with either insulin or saline solution (C). Representative Western blots were obtained using the antibodies indicated. Blots were quantified and the p-S6(S235-236):vinculin, S6K1:vinculin, $p-S 6 K 1(T 389): S 6 K 1$ and p-S6K1(T421/S424):S6K1 ratios were determined. Values are means $(n 6-7)$, with their standard errors represented by vertical bars. They were analysed using two-way ANOVA. There was no diet $X$ treatment interaction, and letters indicate significant differences between the experimental diets at $P<0.05$. au, Arbitrary units. 
(A)

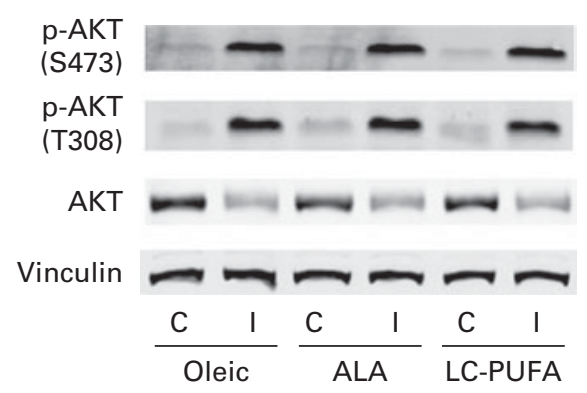

(C)

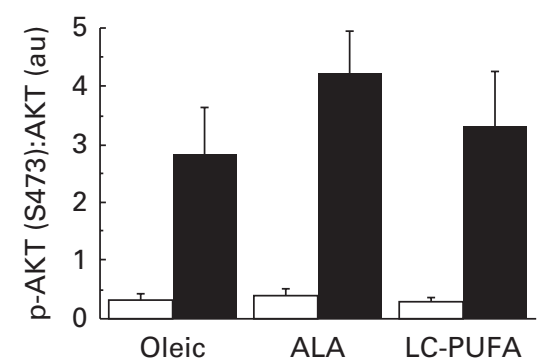

(B)

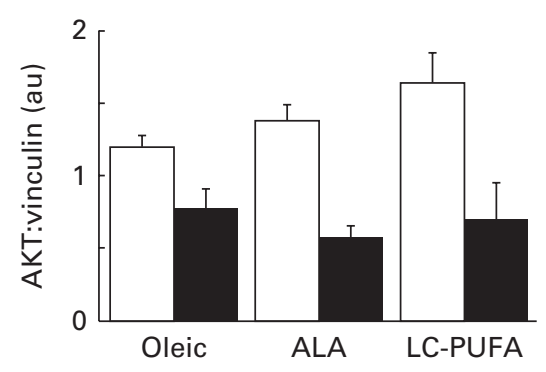

(D)

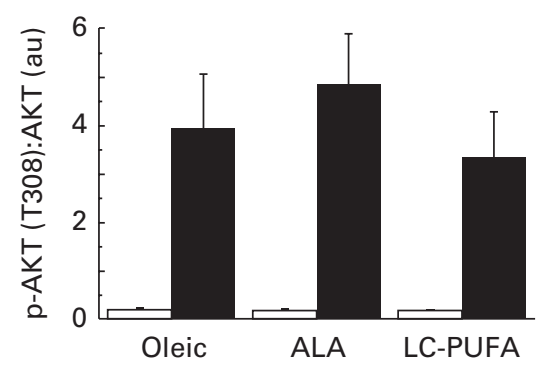

Fig. 2. Effects of insulin injection on protein kinase $B(A K T)$ phosphorylation (p) levels in the breast muscle of 23-d-old chickens fed the Oleic (diet containing oleic sunflower oil rich in monounsaturated 18:1), $\alpha$-linolenic acid (ALA, diet enriched with ALA from rapeseed and linseed oils) and long-chain PUFA (LC-PUFA, diet enriched with LC $n$-3 PUFA from fish oil) experimental diets. The phosphorylation of AKT in chickens food-deprived for $16 \mathrm{~h}$ and injected intravenously with either insulin $(I, \mathbf{\square})$ or saline solution (control, $C(\square)$ ). Representative $(A)$ Western blots were obtained using the antibodies indicated. Blots were quantified and the (B) AKT:vinculin, (C) p-AKT(S473):AKT and (D) p-AKT(T308):AKT ratios were determined. Values are means $(n 6-7)$, with their standard errors represented by vertical bars. They were analysed using two-way ANOVA. There was no diet $\times$ treatment interaction, and no significant differences between the experimental diets at $P<0.05$. au, Arbitrary units.

experimental conditions of the present study, the levels of mRNA expression of atrogin-1 and MuRF1 were not modified by either the treatment or the diet (Fig. S1, available online).

\section{Insulin signalling and gene expression in the liver}

To assess whether dietary $n$ - 3 PUFA affected the insulin cascade in other tissues, we examined the activation of two key signalling proteins involved in insulin action (i.e. AKT and S6) in the liver. We did not focus on S6K1, since its phosphorylation at T389 and T421/S424 in chicken livers was very low and difficult to detect in spite of using a relatively high amount of protein ${ }^{(20,32)}$. As in the breast muscle, insulin drastically increased the phosphorylation of AKT and S6 in the liver $(P<0.001)$ (Fig. 3). There was an effect of diet and an interaction between diet and treatment, irrespective of the effectors considered. Lower insulin-induced phosphorylation levels were found in groups fed the diets enriched with $n-3$ PUFA (ALA for p-AKT and ALA and LC-PUFA for p-S6) compared with the levels in chickens fed the Oleic diet $(P<0.05)$. We next investigated whether gene expression could be altered in the liver, with specific focus on genes involved in lipid metabolism. No effect of treatment (insulin $v$. control) or an interaction between diet and treatment was found, with measurements being carried out only $15 \mathrm{~min}$ after insulin injection. Data obtained from insulin-treated and control chickens were thus pooled and analysed together for the effect of diet (Fig. 4). The expression of FADS1 (involved in FA desaturation) and MTTP (involved in TAG transfer) was reduced in both the ALA and LC-PUFA groups compared with that in the Oleic group $(P<0.05)$. The expression of two lipogenesis-related genes (SREBP1 and SCD1) was also significantly lower in chickens fed the diets enriched with $n-3$ PUFA ( $v$. the Oleic diet), but the differences were particularly marked for the LC-PUFA group, with the ALA group exhibiting intermediate values $(P<0.05)$. The mRNA levels of DGAT2 (involved in TAG synthesis), FAS (involved in lipogenesis), Cd36 (involved in LC-FA uptake), and $P P A R \delta$ and $P P A R \gamma$ (involved in lipoprotein metabolism, lipogenesis and insulin sensitivity) were significantly lower in the LC-PUFA group than in the Oleic group, whereas they did not differ between the ALA and Oleic groups. A similar pattern of expression was found for the ChREBP (involved in lipogenesis), although differences did not reach statistical significance. On the other hand, mRNA abundance for two genes involved in the $\beta$-oxidation process tended to be higher ( $h C P T 1$ ) or was significantly higher $(P P A R \alpha)$ in the ALA group than in both the Oleic and LC-PUFA groups, in which levels were similar.

\section{Discussion}

Under the experimental conditions of the present study, the provision of one of the two diets enriched with $n-3$ PUFA for 3 weeks improved the growth performance of chickens. In addition, both the ALA and LC-PUFA diets led to lower 
(A)
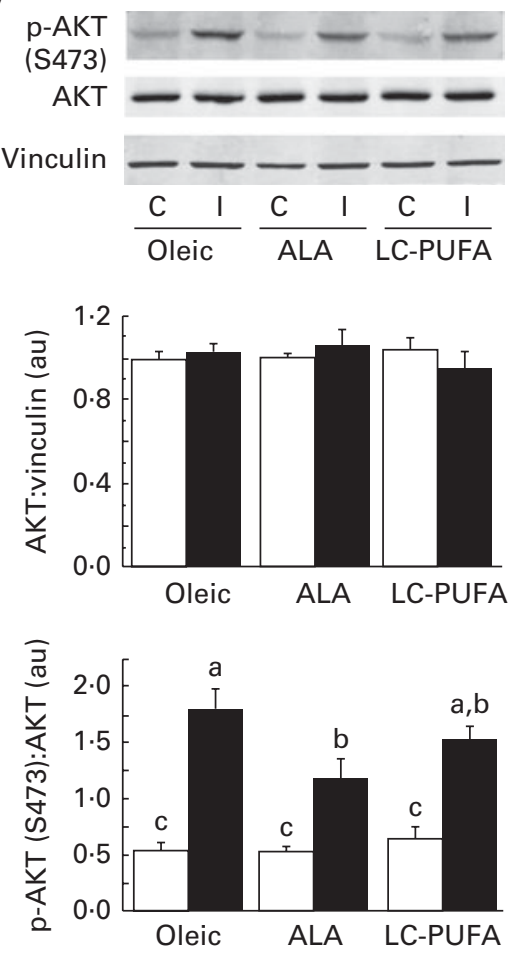

(B)
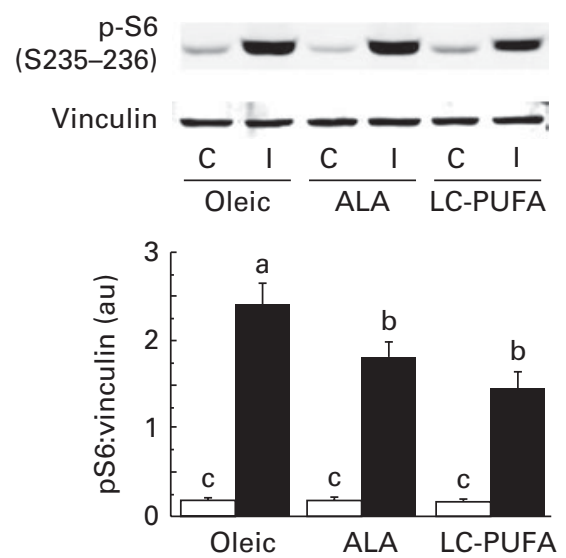

Fig. 3. Effects of insulin injection on protein kinase $B$ (AKT) and ribosomal protein S6 (S6) phosphorylation (p) levels in the livers of 23-d-old chickens fed the Oleic (diet containing oleic sunflower oil rich in monounsaturated 18:1), $\alpha$-linolenic acid (ALA, diet enriched with ALA from rapeseed and linseed oils) and long-chain PUFA (LC-PUFA, diet enriched with LC $n$-3 PUFA from fish oil) experimental diets. The phosphorylation of (A) AKT and (B) S6 in chickens food-deprived for $16 \mathrm{~h}$ and injected intravenously with either insulin (I, $\square$ ) or saline solution (control, C ( $\square$ )). Representative Western blots were obtained using the antibodies indicated. Blots were quantified and the AKT:vinculin, p-AKT(S473):AKT and p-S6(S235-236):vinculin ratios were determined. Values are means $(n 6-7)$, with their standard errors represented by vertical bars. They were analysed using two-way ANOVA. There was a diet $\times$ treatment interaction. ${ }^{a, b, c}$ Mean values were significantly different between the six groups $(P<0.05)$. au, Arbitrary units.

liver lipid content and consistently reduced the hepatic expression of genes involved in FA desaturation, TAG transfer and lipogenesis compared with the Oleic diet. It should be noted that the liver is the main site of lipid synthesis in birds ${ }^{(33)}$. More specifically, enriching the diet with the plant precursor ALA led to particular effects as it may promote $\beta$-oxidation in the liver (e.g. increased PPAR $\alpha$ expression), whereas the diet enriched with LC-PUFA did not lead to any effects. On the other hand, the LC-PUFA diet led to more pronounced changes in body composition and parameters related to lipid metabolism compared with the other two diets: increased liver weight; decreased plasma concentrations of TAG; drastically reduced expression of several genes involved in hepatic lipogenesis. However, the consumption of this diet did not change the percentage of abdominal fat, an indicator of fatness in chickens ${ }^{(34)}$. Interestingly, the diets enriched with ALA enhanced the development of the pectoralis major muscle. Although the issue of protein synthesis $v$. degradation was not addressed in the present study, such an anabolic response in this muscle (entirely fast-twitch glycolytic fibre type) is probably dependent on muscle type, since it is not found in the sartorius muscle (mixed fibre type). This is in good agreement with the fact that highly fast-twitch glycolytic muscles have been reported to respond the most to nutritional factors in terms of variation in protein turnover compared with slow-twitch oxidative muscles in growing rats and chickens ${ }^{(35,36)}$.

Phenotypic differences according to dietary FA were accompanied by changes in FA composition of the liver and leg muscles. This result is interesting because most studies on the modulation of FA composition in chickens have been carried out during the finishing period in broilers (standard chickens aged 35-42d) (for a review, see Kouba $\&$ Mourot $^{(37)}$ ). In the present study, experimental diets were given throughout the rearing period $(21 \mathrm{~d})$ and they contained approximately $7 \cdot 4 \%$ total fat (standard value for diets in fastgrowing chickens). Thus, early and short dietary manipulation would be effective in modifying FA composition in broilers, as has been reported for pigs by Kouba \& $\operatorname{Mourot}^{(37)}$ or in a recent study in chickens ${ }^{(38)}$. Despite the relatively short experimental period and low dietary lipid content, the enrichment of diets with ALA and $n$-3 LC-PUFA was well reflected by the FA enrichment of the liver and muscles with ALA and LC $n$-3 PUFA. However, some particular features were found for specific FA. For example, there was a non-negligible proportion of EPA in the liver $(20: 5 n-3)$ in the Oleic group, despite the low dietary $n-3$ FA provision. This might be consistent with the very high expression of FADS1 in chickens fed this diet compared with the expression in those fed the other two diets, with FADS1 being one of the desaturases required for the formation of EPA. The percentages of DHA (22:6n-3) were especially high in the liver compared with those provided in the diets, whereas the values remained relatively low in the leg muscles. The low percentage of $n-3$ LC-PUFA in the leg muscles compared with the percentage in the liver was still not explained, but it could result from a defect in the export of these FA or a lack of their uptake by muscles and/or preferential oxidation. We also confirmed that enriching a diet with $n-3$ FA decreased the synthesis of $20: 4 n-6$, as there is competition for elongases and desaturases involved in LC-PUFA synthesis from $18: 2 n-6$ and $18: 3 n-6^{(39)}$.

The fact that $n$-3 PUFA enhance breast muscle development, at least in the case of provision of a diet enriched 

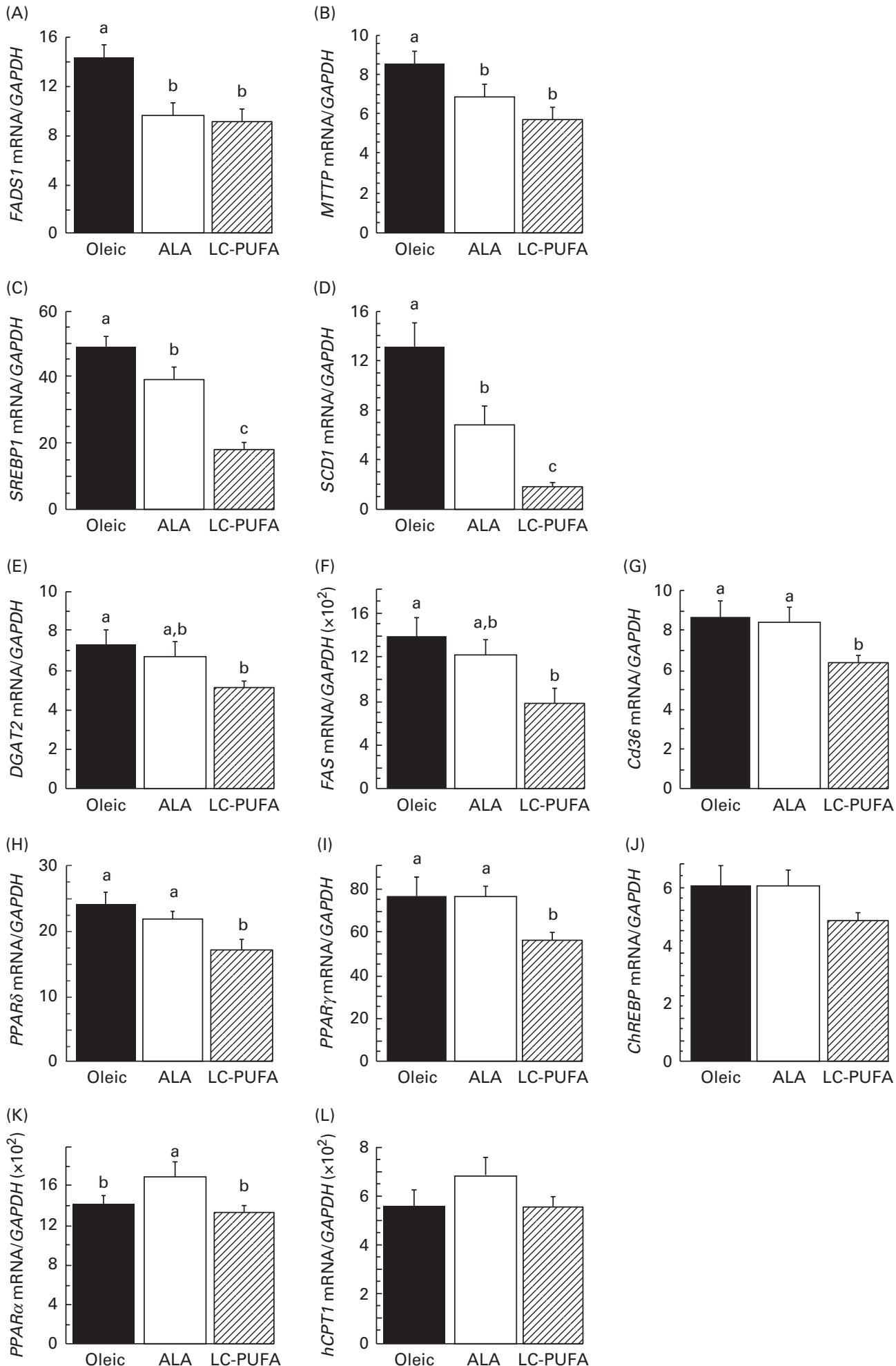

Fig. 4. Gene expression in the livers of 23-d-old chickens fed the Oleic (diet containing oleic sunflower oil rich in monounsaturated 18:1), $\alpha$-linolenic acid (ALA diet enriched with ALA from rapeseed and linseed oils) and long-chain PUFA (LC-PUFA, diet enriched with LC $n$-3 PUFA from fish oil) experimental diets. The relative expression of each gene (i.e. corrected for GAPDH mRNA, which did not differ significantly according to the group) was determined by real time RT-PCR. Values are means $(n 13-14)$, with their standard errors represented by vertical bars. They were analysed using one-way ANOVA. ${ }^{a, b, c}$ Mean values were significantly different between the groups $(P<0.05)$. (A) FADS1, fatty acid desaturase 1 or delta-5 desaturase; (B) MTTP, microsomal TAG transfer protein; (C) $S R E B P 1$, sterol regulatory element-binding protein 1; (D) SCD1, stearoyl-CoA desaturase 1 or delta-9 desaturase; (E) DGAT2, diacylglycerol O-acyltransferase 2;

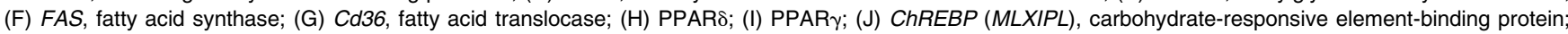
(K) PPAR $\alpha$; (L) $h C P T 1$, hepatic carnitine palmitoyltransferase 1. (A, B) Oleic $\geq$ ALA, LC-PUFA (fatty acid desaturation, TAG transfer). (C, D) Oleic $>$ ALA $>$ LCPUFA (lipogenesis). (E-J) Oleic, ALA $\geq$ LC-PUFA (lipogenesis, insulin resistance, LC-fatty acid uptake). (K, L) ALA $\geq$ Oleic, LC-PUFA ( $\beta$-oxidation). 
with the plant precursor ALA, suggests an action on muscle anabolism. The literature concerning the effect of PUFA on protein metabolism mainly refers to catabolic conditions occurring during sepsis, cancer or immobilisation ${ }^{(40-43)}$ and to insulin resistance ${ }^{(44)}$. However, more recent reports have shown that the consumption of $n$-3 LC-PUFA promotes muscle anabolism in both farm animals ${ }^{(3)}$ and humans ${ }^{(4,5)}$. One of the mechanisms that have been proposed is associated with the enhanced activation of the insulin cascade, as this hormone controls the protein synthesis/proteolysis balance. Consistent with this is the fact that the ALA-enriched diet appeared to induce higher levels of activation of the insulindependent S6K1/S6 pathway in the breast muscle. This is in agreement with the results obtained by Gingras et $a l^{(3)}$ and Smith et $a l .{ }^{(4,5)}$ using $n$-3 LC-PUFA diets. In contrast, we did not find any improvement in insulin sensitivity in muscles with the LC-PUFA diet. Under the experimental conditions of the present study (e.g. single collection $15 \mathrm{~min}$ after insulin treatment), the mRNA levels of genes involved in proteolysis (i.e. atrogenes) were not affected by insulin administration or by dietary $n-3$ enrichment. Whether both components of protein turnover (i.e. protein synthesis and proteolysis) are affected by $n-3$ PUFA is still unclear. Nevertheless, $15 \mathrm{~min}$ were probably too short to induce any insulin-related change in the expression of atrogenes ${ }^{(45)}$. On the other hand, our findings are in contrast with previous evidence that dietary fish oils could modulate the expression of MuRF1 and atrogin-1 in rats ${ }^{(43)}$. It is important to note that this mechanism may involve the AKT signalling pathway, but in the present study, the provision of $n-3$ PUFA diets did not lead to a significant activation of AKT. Moreover, the beneficial effect of fish oils has previously been reported in catabolic conditions, i.e. alleviating immobilisation-induced muscle atrophy ${ }^{(43)}$, and not in anabolic conditions characteristic of muscle growth, as in the present study.

We cannot exclude the possibility that the $n-3$ PUFA levels provided by the LC-PUFA diet were too low (half of the $n$-3 PUFA levels provided by the ALA diet leading to a twice lower $n$-3 FA content in muscles) to exert a significant effect on protein anabolism/catabolism in muscles. Alternatively, a specific effect of ALA on insulin signalling in muscles should be considered. Indeed, in contrast to that observed in the breast muscle, insulin-induced phosphorylation levels of AKT and $\mathrm{S} 6$ in the liver were lower in the ALA and/or LC-PUFA groups than in the Oleic group. Such tissue specificity of the effect of an $n$ - 3 FA diet has been reported previously, since $n-3$ LC-PUFA enrichment of a high-fat diet prevented defective insulin receptor signalling in muscles but not in the liver ${ }^{(46)}$. The basic mechanisms sustaining the tissue-specific effects of $n$-3 PUFA (ALA and/or LC-PUFA) on insulin signalling remain unclear. One hypothesis is that these differential effects may be due to certain differences in FA composition between the liver and muscles, as reflected in the present study by the tissue-specific FA profile. It has long been established that dietary $n$ - 3 PUFA composition influences the composition of stored and structural lipids, including membrane lipids, thereby modifying insulin action via changes in membrane fluidity and insulin receptor binding ${ }^{(47)}$.
Moreover, membrane FA composition is, in particular, changed at the level of lipid rafts and caveolin microdomains modifying signal transduction, microlocalisation of different signalling proteins and trafficking ${ }^{(48,49)}$. For example, there is evidence that the membrane adaptator caveolin-1 is involved in the regulation of AKT signalling ${ }^{(50)}$. Nevertheless, the underlying mechanisms are certainly very complex. The $n$-3 LC-PUFA enrichment of membrane rafts affects various signalling pathways depending on the cell line involved ${ }^{(48)}$. The effects observed may also depend on the individual PUFA, as has been suggested by a recent in vitro study ${ }^{(51)}$, and may be different for ALA compared with its longer-chain counterparts, and this still requires investigation.

In conclusion, we report improved growth in chickens fed diets enriched with PUFA, i.e. rich in LC-PUFA as well as the precursor ALA, for a short period. Our findings also indicate that only the ALA-enriched diet providing the highest levels of $n$-3 FA (about $16 \%$ of total FA) leads to increased pectoralis major muscle weight, related to a higher $n-3$ FA content and to a higher level of activation of the insulin-dependent S6K1/S6 pathway involved in the translation of mRNA into proteins. The mechanisms through which $n-3$ PUFA are able to modulate insulin sensitivity and their consequences on anabolic processes remain to be characterised. Our findings provide a basis on which to optimise dietary FA provision. Such nutritional strategies could be used to improve feed utilisation and optimise body composition and meat quality while ensuring the efficiency of production systems.

\section{Supplementary material}

To view supplementary material for this article, please visit http://dx.doi.org/10.1017/S0007114513003085

\section{Acknowledgements}

The authors thank P. Moritz and F. Mercerand (INRA, UE1295 PEAT, Nouzilly, France) for animal care and experimental design management; E. Cailleau-Audouin, S. Crochet, J. David, N. Flamion, J. M. Hallouis and T. Bordeau (INRA, UR83 Recherches Avicoles, Nouzilly, France) for their technical assistance; and C. Diot for his expertise on primers used in the quantification of the expression of genes involved in hepatic lipid metabolism. They are also grateful to D. Raine (Surrey, UK) for editing the article.

The present study was supported by Research Grants from ONIDOL and INRA; both contributed to the study design and manuscript preparation. The funder INRA also contributed to the conduct of the study, analysis of the samples and data, and interpretation of the findings.

The authors' contributions were as follows: D. H., N. S., C. P., M. L. and S. T. contributed to the conception and design of the study; P. C., S. M.-C. and E. B. were involved in the acquisition of the data; P. C., E. B. and S. T. analysed and interpreted the data. All authors were involved in the writing of the final draft of the manuscript and approved the final format.

None of the authors has any conflicts of interest. 


\section{References}

1. Mandard S, Muller M \& Kersten S (2004) Peroxisome proliferator-activated receptor alpha target genes. Cell Mol Life Sci 61, 393-416.

2. Bergeron K, Julien P, Davis TA, et al. (2007) Long-chain $n-3$ fatty acids enhance neonatal insulin-regulated protein metabolism in piglets by differentially altering muscle lipid composition. J Lipid Res 48, 2396-2410.

3. Gingras AA, White PJ, Chouinard PY, et al. (2007) Longchain omega-3 fatty acids regulate bovine whole-body protein metabolism by promoting muscle insulin signalling to the Akt-mTOR-S6K1 pathway and insulin sensitivity. J Physiol 579, 269-284.

4. Smith GI, Atherton P, Reeds DN, et al. (2011) Omega-3 polyunsaturated fatty acids augment the muscle protein anabolic response to hyperinsulinaemia-hyperaminoacidaemia in healthy young and middle-aged men and women. Clin Sci 121, 267-278.

5. Smith GI, Atherton P, Reeds DN, et al. (2011) Dietary omega-3 fatty acid supplementation increases the rate of muscle protein synthesis in older adults: a randomized controlled trial. Am J Clin Nutr 93, 402-412.

6. Tesseraud S, Métayer S, Duchêne S, et al. (2007) Regulation of protein metabolism by insulin: value of different approaches and animal models. Domest Anim Endocrinol 33, 123-142.

7. Bigot K, Taouis M \& Tesseraud S (2003) Refeeding and insulin regulate S6K1 activity in chicken skeletal muscles. J Nutr 133, 369-373.

8. Duchene S, Audouin E, Crochet S, et al. (2008) Involvement of the ERK 1/2 MAPK pathway in insulin-induced S6K1 activation in avian cells. Domest Anim Endocrinol 34, 63-73.

9. Duchene S, Métayer S, Audouin E, et al. (2008) Refeeding and insulin activate the AKT/p70S6 kinase pathway without affecting IRSI tyrosine phosphorylation in chicken muscle. Domest Anim Endocrinol 34, 1-13.

10. Tesseraud S, Abbas M, Duchene S, et al. (2006) Mechanisms involved in the nutritional regulation of mRNA translation: features of the avian model. Nutr Res Rev 19, 104-116.

11. Bodine SC, Latres E, Baumhueter S, et al. (2001) Identification of ubiquitin ligases required for skeletal muscle atrophy. Science 294, 1704-1708.

12. Gomes MD, Lecker SH, Jagoe RT, et al. (2001) Atrogin-1, a muscle-specific F-box protein highly expressed during muscle atrophy. Proc Natl Acad U S A 98, 14440-14445.

13. Clarke BA, Drujan D, Willis MS, et al. (2007) The E3 Ligase MuRF1 degrades myosin heavy chain protein in dexamethasonetreated skeletal muscle. Cell Metab 6, 376-385.

14. Cohen S, Brault JJ, Gygi SP, et al. (2009) During muscle atrophy, thick, but not thin, filament components are degraded by MuRF1-dependent ubiquitylation. I Cell Biol 185, 1083-1095.

15. Attaix D \& Baracos VE (2010) MAFbx/Atrogin-1 expression is a poor index of muscle proteolysis. Curr Opin Clin Nutr Metab Care 13, 223-224.

16. Stitt TN, Drujan D, Clarke BA, et al. (2004) The IGF-1/PI3K/ Akt pathway prevents expression of muscle atrophy-induced ubiquitin ligases by inhibiting FOXO transcription factors. Mol Cell 14, 395-403.

17. Nader GA (2005) Molecular determinants of skeletal muscle mass: getting the "AKT" together. Int J Biochem Cell Biol 37, $1985-1996$

18. Tesseraud S, Métayer-Coustard S, Boussaid S, et al. (2007) Insulin and amino acid availability regulate atrogin-1 in avian QT6 cells. Biochem Biophys Res Commun 357, $181-186$

19. Marche $\mathrm{G}$ (2000) La découpe anatomique et la dissection des volailles (Anatomic Carcass Processing and Dissection in Poultry) [SYSAAF and INRA, editors]. Nouzilly: SYSAAF and INRA.

20. Dupont J, Tesseraud S, Derouet M, et al. (2008) Insulin immuno-neutralization in chicken: effects on insulin signaling and gene expression in liver and muscle. $J$ Endocrinol 197, 531-542.

21. Fossati P \& Prencipe L (1982) Serum triglycerides determined colorimetrically with an enzyme that produces hydrogen peroxide. Clin Chem 28, 2077-2080.

22. Artiss JD \& Entwistle WM (1981) The application of a sensitive uricase-peroxidase coupled reaction to a centrifugal fast analyser for the determination of uric acid. Clin Chim Acta 116, 301-309.

23. Trinder P (1969) Determination of blood glucose using 4-amino phenazone as oxygen acceptor. J Clin Pathol 22, 246.

24. Monin G \& Sellier P (1985) Pork of low technological quality with a normal rate of $\mathrm{pH}$ fall in the intermediate post mortem period: the case of the Hampshire breed. Meat Sci 13, 49-63.

25. Dalrymple RH \& Hamm R (1973) A method for extraction of glycogen and metabolites from a single muscle sample. J Food Technol 8, 439-444.

26. Folch J, Lees M \& Sloane Stanley GH (1957) A simple method for the isolation and purification of total lipides from animal tissues. J Biol Chem 226, 497-509.

27. Morrisson WR \& Smith ML (1964) Preparation of fatty acid methyl esters and dimethylacetates from lipid with boron trifluoride methanol. J Lipid Res 5, 600-608.

28. Tesseraud S, Bouvarel I, Collin A, et al. (2009) Daily variations in dietary lysine content alter the expression of genes related to proteolysis in chicken pectoralis major muscle. J Nutr 139, 38-43.

29. Joubert R, Métayer Coustard S, Swennen Q, et al. (2010) The beta-adrenergic system is involved in the regulation of the expression of avian uncoupling protein in the chicken. Domest Anim Endocrinol 38, 115-125.

30. Hérault F, Saez G, Robert E, et al. (2010) Liver gene expression in relation to hepatic steatosis and lipid secretion in two duck species. Anim Genet 41, 12-20.

31. Chabrolle C, Tosca L, Crochet S, et al. (2007) Expression of adiponectin and its receptors (AdipoR1 and AdipoR2) in chicken ovary: potential role in ovarian steroidogenesis. Domest Anim Endocrinol 33, 480-487.

32. Duchene S, Audouin E, Berri C, et al. (2008) Tissue-specific regulation of $56 \mathrm{~K} 1$ by insulin in chickens divergently selected for growth. Gen Comp Endocrinol 156, 190-198.

33. Leveille GA, Romsos DR, Yeh Y, et al. (1975) Lipid biosynthesis in the chick. A consideration of site of synthesis, influence of diet and possible regulatory mechanisms. Poult Sci 54, 1075-1093.

34. Cahaner A, Nitsan Z \& Nir I (1986) Weight and fat content of adipose and non-adipose tissues in broilers selected for or against abdominal adipose tissue. Poult Sci 65, 215-222.

35. Baillie AG \& Garlick PJ (1991) Responses of protein synthesis in different skeletal muscles to fasting and insulin in rats. Am J Physiol Endocrinol Metab 260, E891-E896.

36. Tesseraud S, Maaa N, Peresson R, et al. (1996) Relative responses of protein turnover in three different skeletal muscles to dietary lysine deficiency in chicks. Br Poult Sci 37, 641-650. 
37. Kouba M \& Mourot J (2011) A review of nutritional effects on fat composition of animal products with special emphasis on n-3 polyunsaturated fatty acids. Biochimie 93, 13-17.

38. Kartikasari LR, Hughes RJ, Geier MS, et al. (2012) Dietary alpha-linolenic acid enhances omega-3 long chain polyunsaturated fatty acid levels in chicken tissues. Prostaglandins Leukot Essent Fatty Acids 87, 103-109.

39. Lessire M (2001) Matières grasses alimentaires et composition lipidique des volailles (Dietary fats and poultry fatty acid composition). INRA Prod Anim 14, 365-370.

40. Khal J \& Tisdale MJ (2008) Downregulation of muscle protein degradation in sepsis by eicosapentaenoic acid (EPA). Biochem Biophys Res Commun 375, 238-240.

41. Smith HJ, Greenberg NA \& Tisdale MJ (2004) Effect of eicosapentaenoic acid, protein and amino acids on protein synthesis and degradation in skeletal muscle of cachectic mice. Br J Cancer 91, 408-412.

42. Whitehouse AS, Smith HJ, Drake JL, et al. (2001) Mechanism of attenuation of skeletal muscle protein catabolism in cancer cachexia by eicosapentaenoic acid. Cancer Res $\mathbf{6 1}$, 3604-3609.

43. You JS, Park MN, Song W, et al. (2010) Dietary fish oil alleviates soleus atrophy during immobilization in association with Akt signaling to p70s6k and E3 ubiquitin ligases in rats. Appl Physiol Nutr Metab 35, 310-318.

44. Sohal PS, Baracos VE \& Clandinin MT (1992) Dietary omega 3 fatty acid alters prostaglandin synthesis, glucose transport and protein turnover in skeletal muscle of healthy and diabetic rats. Biochem J 286, 405-411.

45. Frost RA, Nystrom GJ, Jefferson LS, et al. (2007) Hormone, cytokine, and nutritional regulation of sepsis-induced increases in atrogin-1 and MuRF1 in skeletal muscle. $A m J$ Physiol Endocrinol Metab 292, E501-E512.

46. Taouis M, Dagou C, Ster C, et al. (2002) N-3 polyunsaturated fatty acids prevent the defect of insulin receptor signaling in muscle. Am J Physiol Endocrinol Metab 282, E664-E671.

47. Liu S, Baracos VE, Quinney HA, et al. (1994) Dietary omega-3 and polyunsaturated fatty acids modify fatty acyl composition and insulin binding in skeletal-muscle sarcolemma. Biochem J 299, 831-837.

48. Anderson BM \& Ma DW (2009) Are all $n$-3 polyunsaturated fatty acids created equal? Lipids Health Dis $\mathbf{8}, 33$.

49. Le Foll C, Corporeau C, Le Guen V, et al. (2007) Long-chain $n-3$ polyunsaturated fatty acids dissociate phosphorylation of Akt from phosphatidylinositol 3'-kinase activity in rats. Am J Physiol Endocrinol Metab 292, E1223-E1230.

50. Sedding DG, Hermsen J, Seay U, et al. (2005) Caveolin-1 facilitates mechanosensitive protein kinase B (Akt) signaling in vitro and in vivo. Circ Res 96, 635-642.

51. Kamolrat T \& Gray SR (2013) The effect of eicosapentaenoic and docosahexaenoic acid on protein synthesis and breakdown in murine C2C12 myotubes. Biochem Biophys Res Commun 432, 593-598. 